\title{
Neural Basis of Embodiment: Distinct Contributions of Temporoparietal Junction and Extrastriate Body Area
}

\author{
Shahar Arzy, ${ }^{1,2,3}$ Gregor Thut, ${ }^{2,4}$ Christine Mohr, ${ }^{2,5}$ Christoph M. Michel,, ${ }^{2,4}$ and Olaf Blanke ${ }^{1,2}$ \\ ${ }^{1}$ Laboratory of Cognitive Neuroscience, Brain Mind Institute, Ecole Polytechnique Fédérale de Lausanne, 1015 Lausanne, Switzerland, ${ }^{2}$ Department of \\ Neurology, University Hospital, 1211 Geneva, Switzerland, ${ }^{3}$ Department of Neurology, Hadassah Hebrew University Hospital, 91120 Jerusalem, Israel, \\ ${ }^{4}$ Department of Fundamental Neuroscience, University Medical School, 1211 Geneva, Switzerland, and 5 Department of Experimental Psychology, \\ University of Bristol, Bristol, BS8 1TH, United Kingdom
}

\begin{abstract}
Embodiment, the sense of being localized within one's physical body, is a fundamental aspect of the self. Recently, researchers have started to show that self and body processing require distinct brain mechanisms, suggesting two posterior brain regions as key loci: the temporoparietal junction (TPJ), which is involved in self processing and multisensory integration of body-related information; and the extrastriate body area (EBA), which responds selectively to human bodies and body parts. Here we used evoked potential mapping and a distributed linear inverse solution to show that activations in EBA and TPJ code differentially for embodiment and self location, because the location and timing of brain activation depended on whether mental imagery is performed with mentally embodied (EBA) or disembodied (TPJ) self location. In a second experiment, we showed that only EBA activation, related to embodied self location, but not TPJ activation, related to disembodied self location, was modified by the subjects' body position during task performance (supine or sitting). This suggests that embodied self location and actual body location share neural mechanisms. Collectively, these data show that distributed brain activity at the EBA and TPJ as well as their timing are crucial for the coding of the self as embodied and as spatially situated within the human body.
\end{abstract}

Key words: embodiment; self; mental imagery; body position; extrastriate body area; EBA; temporoparietal junction; TPJ

\section{Introduction}

Although the average reader probably has never had any trouble localizing himself within his own bodily borders, this sense of self location or embodiment requires specific brain mechanisms, which we are only now beginning to understand (Jeannerod, 2003; Metzinger, 2003; Blanke et al., 2004, 2005). Converging evidence from the nascent field of neuroscience of the self suggests that two posterior brain regions might be crucial in self and body processing and probably also embodiment and self location. The extrastriate body area (EBA) in lateral occipitotemporal cortex responds selectively to images of human bodies and body parts (Downing et al., 2001; Astafiev et al., 2004) but also to imagined movements of one's own body as well as executed movements (Astafiev et al., 2004). This shows that the EBA integrates multisensory body-related information and suggests its role in self processing (Astafiev et al., 2004; Jeannerod, 2004; Peelen and Downing, 2005). Cortex at the temporoparietal junction (TPJ) has also been shown to integrate multisensory bodyrelated information (Leube et al., 2003) and to code for several

Received Feb. 19, 2006; revised June 13, 2006; accepted June 25, 2006.

This work was supported by the Fondation de Famille Sandoz and the Fondation Leenaards. We thank Istvan Molnar-Szakacs and Thomas Metzinger for helpful comments on a previous version of this manuscript and Denis Brunet for his excellent software, Cartool, and his technical assistance in data analysis. We thank Silvia Buenning for her help with data recording, and Olga Prilipko for the illustration of Figure $1 B$.

Correspondence should be addressed to Dr. Olaf Blanke, Laboratory of Cognitive Neuroscience, Brain Mind Institute, Ecole Polytechnique Fédérale de Lausanne, Station 15, 1015 Lausanne, Switzerland. E-mail: olaf.blanke@epfl.ch.

DOI:10.1523/JNEUROSCI.0745-06.2006

Copyright $\odot 2006$ Society for Neuroscience $\quad$ 0270-6474/06/268074-08\$15.00/0 aspects of self-processing, such as agency, self-other distinction, and mental own-body imagery (Maguire et al., 1998; Zacks et al., 1999; Ruby and Decety, 2001; Vogeley and Fink, 2003; Blanke and Arzy, 2005). Moreover, recent clinical and neuroimaging data suggest that the TPJ is involved in coding embodiment. Interference with this area in neurological patients may lead to the experience of disembodiment (Blanke et al., 2002, 2004), and, in healthy subjects, mental imagery using disembodied self location also activates the TPJ (Zacks et al., 1999; Blanke et al., 2005). Whereas the role of the TPJ in self processing has often been investigated, much less is known about self processing in EBA (Saxe and Kanwisher, 2003; Jeannerod, 2004).

Here we used two mental-imagery tasks asking subjects to make judgments about human bodies after having imagined that the depicted human bodies represent their own body. Importantly, subjects performed this task from a mentally embodied or disembodied self location. By applying evoked potential (EP) mapping and a distributed linear inverse solution, we show that mental own-body imagery activates cortex in EBA and the TPJ and that location and timing of these activations depend on whether mental self location is embodied or disembodied. In a second experiment, we show that the subject's physical body position interferes selectively with EBA activation related to embodied self location but not with TPJ activation related to disembodied self location. These results suggest that the sense of embodiment is linked to activation patterns in EBA and the TPJ and that imagined self location and actual body location share neural mechanisms. 
A

MIR-task

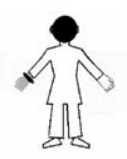

right

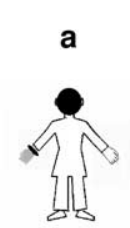

left

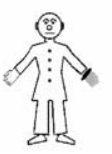

right

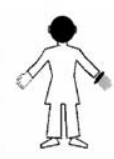

left

C

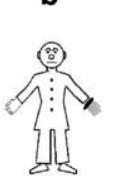

left

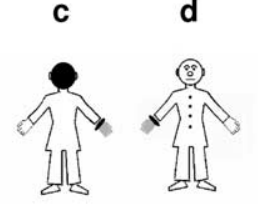

right

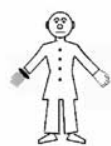

left

right

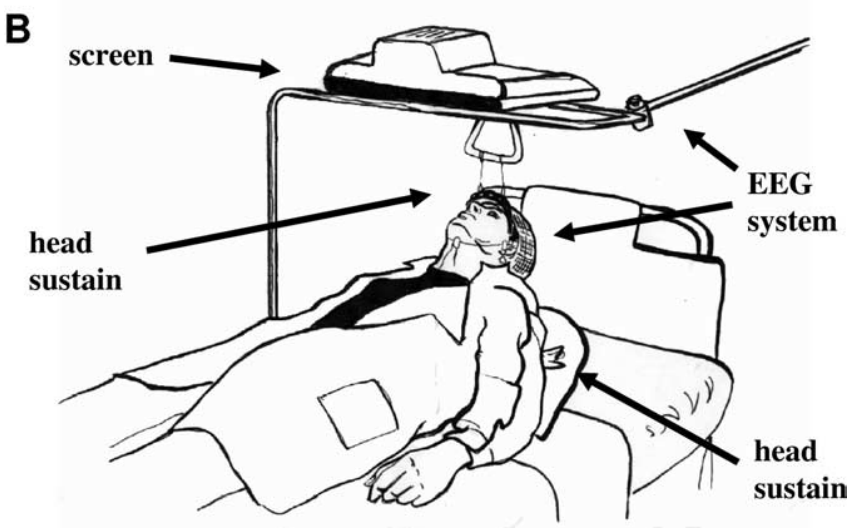

Figure 1. Stimuli and setup. $\boldsymbol{A}$, Stimuli. The four different stimuli as used in the MIR task (top) and the OBT task (bottom) are shown. Correct responses in both tasks are indicated below each figure. $\boldsymbol{B}$, Experimental setup of the supine position (experiment 2 ).

\section{Materials and Methods}

Participants. Fourteen healthy volunteers (all males; aged 20-35 years; mean \pm SD, $26.2 \pm 4.6$ years) participated in experiment 1 . Ten subjects (five females; aged $19-35$ years; $27.5 \pm 3.2$ years) participated in experiment 2. All participants were right-handed, had normal or corrected-tonormal vision, and declared having no history of neurological or psychiatric disorders. All participants gave written informed consent before inclusion in the study, which had been approved by the Ethical Committee of the University Hospital of Geneva (Switzerland).

Stimuli and procedure. To investigate embodiment and self location, we asked subjects to perform two mental-imagery tasks with respect to their own body in response to a schematic front- or back-facing human figure. In an own-body transformation task, (OBT task) subjects were asked to imagine themselves in the position and orientation of a schematic human figure, as shown on a computer screen (Fig. $1 \mathrm{~A}$, bottom row, the correct responses for each task are indicated under each stimulus) (Zacks et al., 1999; Blanke et al., 2005). Either the right or left hand of the figure was marked, and subjects indicated which hand was marked. In a mirror task (MIR task), the same schematic human figure was shown, but subjects were instructed to imagine that the schematic figure (as shown on the computer screen) was their mirror reflection, as seen from their habitual point of view (Fig. $1 \mathrm{~A}$, top row, the correct responses for each task are indicated under each stimulus).

Both tasks involved the same visual stimuli (human figure), the same rotation of the visuospatial perspective (front- and back-facing), and the same response mode (manual response). However, in the OBT task, subjects imagined themselves at an extracorporeal position (or disembodied self location), whereas in the MIR task, they imagined themselves at their habitual intracorporeal position (or embodied self location). Extending previous experimental (Blanke et al., 2005) and clinical findings on pathological forms of embodiment as well as disembodiment (Blanke et al., 2004; Blanke and Mohr, 2005), we here hypothesized that differences in self location (embodied vs disembodied) in the present experiment would be reflected behaviorally and with respect to activated brain regions. Front- and back-facing figures had the same dimensions $\left(5.0 \times 6.1^{\circ}\right.$ of visual angle $)$ and differed only in the rendering of the clothing of the figure and the presence of a face or the back of a head (Fig. $1 A$, schematic figures $a, c$ vs $b, d$ ). Stimuli appeared for $200 \mathrm{~ms}$ in the center of the computer screen, with an interstimulus interval of $2800 \mathrm{~ms}$ in the first experiment and $2000 \mathrm{~ms}$ in the second experiment (the shorter interstimulus interval in experiment 2 was chosen to diminish the duration of the experiment, thus facilitating acquisition of more trials while minimizing the time subjects had to spend in an uncomfortable position; see below). Left-right judgments were given via a button press on a serial response box. Responses were given using index and middle fingers of the left and right hand in alternating blocks. The participants were repeatedly instructed to respond as fast and precisely as possible but always to perform the requested mental imagery in both tasks before giving the response.

In experiments 1 and 2, MIR and OBT tasks were performed in an alternating manner in a total of eight blocks (same task performed over a given block). Half of the participants began with the MIR task and half with the OBT task. In experiment 1, within blocks, each of the four stimuli appeared 10 times in randomized order, giving rise to 40 visual presentations per block. In experiment 2, participants performed the MIR and OBT tasks in two different body positions (same blocks and stimulus presentation). They first performed the two tasks over four blocks in a supine position, immediately followed by four blocks in a sitting position (for the experimental setup and the apparatus that had been designed for electroencephalographic (EEG) recordings in the supine position, see Fig. $1 \mathrm{~B}$ ). Within blocks, each stimulus appeared 30 times, giving rise to 120 presentations per block. The supine position preceded the sitting position for technical reasons, caused by the EEG settings in the former position, as reported also by others (Alonso et al., 1989). The same computer screen and distance of the subjects' eyes from the monitor were used for recordings in the two body positions.

As a control experiment to experiment 2, we also recorded visual EPs to central checkerboard stimuli $\left(5.2^{\circ}\right.$ of visual angle; reversal at $0.5 \mathrm{~Hz}$; $n=200$ stimuli). These were presented in the supine and sitting sessions before the MIR and OBT tasks. Participants were instructed to fixate a central gray cross $\left(1 \mathrm{~cm} ; \sim 1.0^{\circ}\right.$ of visual angle $)$ in the middle of the checkerboard.

Analysis of behavioral data. In experiment 1, repeated-measures ANOVAs were run on reaction times (RTs) with the factors task (MIR vs OBT) and orientation (back-facing vs front-facing). In experiment 2, repeatedmeasures ANOVAs were run on RTs with the factors task (MIR vs OBT), orientation (back-facing vs front-facing), and position (supine vs sitting).

EEG recording, EP mapping, and distributed linear inverse solution. Continuous EEG was acquired with a Geodesics Netamps system (Electrical Geodesics, Eugene, OR) from 123 scalp electrodes (impedances $<50 \mathrm{k} \Omega$; vertex referenced; $500 \mathrm{~Hz}$ digitization; bandpass filtered, $0.1-$ $200 \mathrm{~Hz}$ ) in a darkened, electrically shielded booth. Epochs of EEG (from 0 to $600 \mathrm{~ms}$ after stimulus onset) from trials yielding correct responses were averaged for each of the four experimental conditions and for each subject to calculate the EPs. In addition to the rejection of sweeps in which any channel exceeded the amplitude of $\pm 100 \mu \mathrm{V}$, the data were visually inspected to reject epochs with blinks, eye movements, or other sources of transient noise. The mean percentage of accepted epochs per condition was $80 \%$ for MIR-back, $81 \%$ for MIR-front, $78 \%$ for OBTback, and $83 \%$ for OBT-front. For each subject's EPs, the electrodes on the outermost circumference (chin and neck) as well as other artifact channels were excluded and interpolated to a standard 111-channel electrode array (two-dimensional spherical spline) (Perrin et al., 1987). After this procedure and before group averaging, EPs were bandpass filtered $(1-40 \mathrm{~Hz})$ and recalculated against the average reference.

$\mathrm{EP}$ analysis was based on the examination of the spatial variations of the scalp voltage distribution over time and between conditions, an approach known as EP mapping (Michel et al., 2001, 2004; Itier and Taylor, 2004; Blanke et al., 2005; Murray et al., 2005). This approach searches for time segments of stable map topography that represent functional microstates of the brain during information processing. EP segments were 
defined by using a spatial $k$ means cluster analysis to identify the dominant map topographies on the scalp in the group-averaged EPs across the experimental conditions over time (Pascual-Marqui et al., 1995; Itier and Taylor, 2004; Blanke et al., 2005). These maps are the mean maps over the period in which the segment was found. The optimal number of these template maps is determined by a modified cross-validation criterion (Pascual-Marqui et al., 1995). In a second step, the presence of a given EP map as identified in the groupaveraged data are verified statistically in the EPs of the individual subjects. This allows to determine the duration of a given EP map for each condition across subjects. These duration values for a given EP map then can be subjected to statistical analysis. Statistical comparisons were performed on the duration of each map (dependent variable) in the individual EPs using repeated-measures ANOVAs, with the factors task (MIR vs OBT) and orientation (backfacing vs front-facing) in experiment 1 and with the additional factor position (sitting vs supine) in experiment 2 . The same analysis was performed for the amplitude of the global field power (GFP) of each map, which is defined as the spatial root mean squared across all electrodes (Lehmann and Skrandies, 1980). In the control experiment for experiment 2 (checkerboard), ANOVAs were run with the factor position on the duration and the GFP amplitude of each map. Finally, the neural generators for a given mean EP map were estimated by applying a distributed linear inverse solution, based on a local autoregressive average [LAURA model (Grave de Peralta Menendez et al., 2001, 2004)].

\section{Results}

Experiment 1: mental own-body imagery for embodied or disembodied self location activates different brain regions

Participants performed differently for tasks related to embodied (MIR) and disembodied (OBT) self location. In the MIR task, RTs were longer for back-facing (mean $\pm \mathrm{SD}, 1154.6 \pm 255.4 \mathrm{~ms}$ ) than front-facing (1043.5 $\pm 210.2 \mathrm{~ms}$ ) stimuli. Replicating previous reports (Parsons, 1987; Zacks et al., 1999; Blanke et al., 2005), the opposite pattern was found in the OBT task (longer RTs for front-facing than back-facing stimuli, $1003.7 \pm 272.2$ vs $880.6 \pm 253.5 \mathrm{~ms}$ ) (Fig. 2A). Statistical analysis revealed a significant task $\times$ orientation (back-facing vs front-facing) interaction $\left(F_{(1,13)}=15.9\right.$; $p=0.001)$, a main effect of task $\left(F_{(1,13)}=51.6 ; p<0.001\right)$, and no significant orientation effect $\left(F_{(1,13)}=0.21 ; p=0.21\right)$ (supplemental Table S1, available at www.jneurosci.org as supplemental material).

There were no differences between MIR and OBT tasks regarding accuracy (mean error rates, $10.1 \pm 8.9 \%$, MIR task; $10.0 \pm 9.2 \%$, OBT task; $\left.F_{(1,13)}=0.02 ; p=0.96\right)$. Subjects' error rates were higher in the back condition than in front condition in the MIR task (mean error rates, $12.3 \pm 10.2 \%$, back; $8.0 \pm 7.5 \%$, front; $F_{(1,13)}=5.5 ; p=0.03$ ). The opposite pattern was found in the OBT task, in which error rates were higher in the front conthe right TPJ and left EBA.
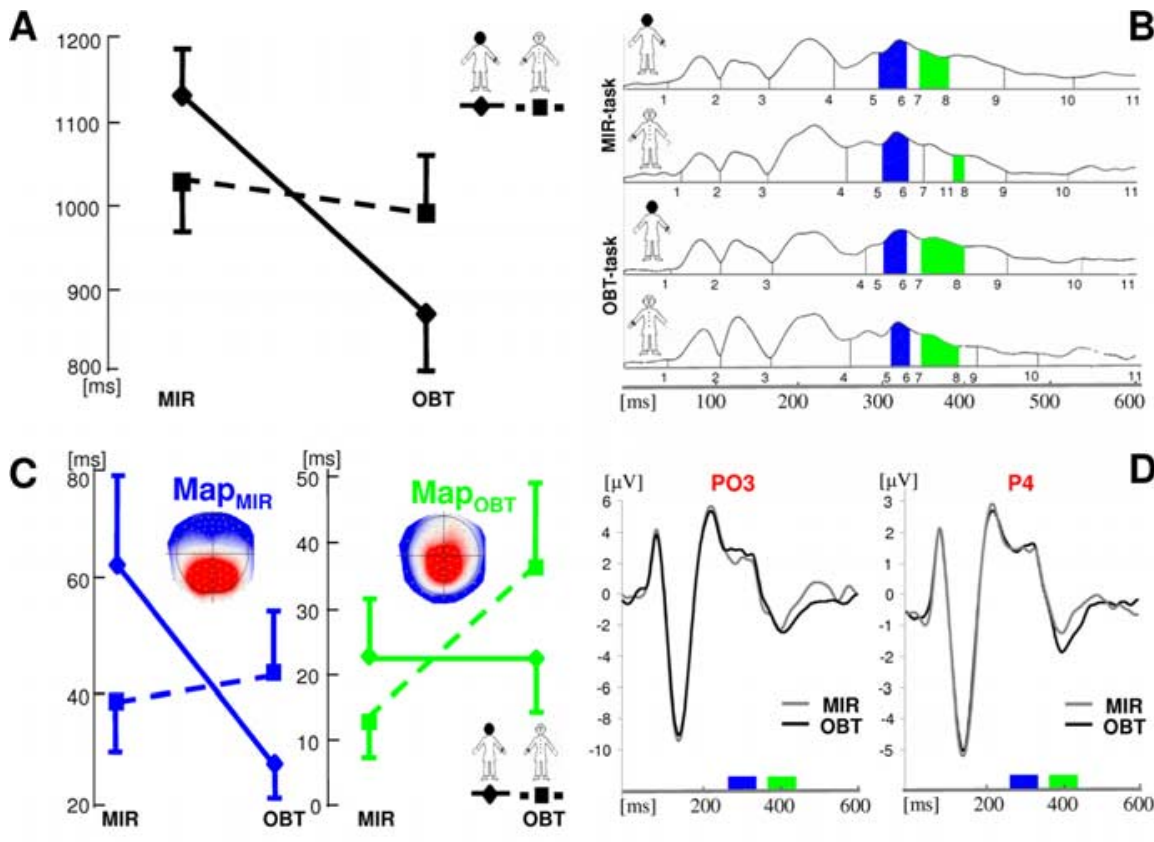

D
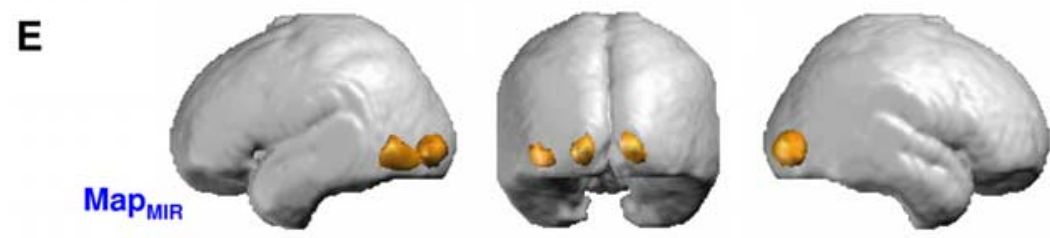

$3.2^{\mathrm{E}} 4_{\mathrm{mm}}^{\text {UA }}$ separately for front-facing (squares, dashed line) and back-facing (diamonds) figures. Error bars indicate intersubject SEM. Note the longer RTs for the MIR than the OBT task. In addition, back-facing figures during the MIR task were characterized by longer RTs topography in the four experimental conditions under the global field power curve from 0 to $600 \mathrm{~ms}$. EP segment 6 (Map $_{\text {MIR }}$. segment shown in blue) was found from $\sim 285$ to 330 ms and was longer for the MIR task than OBT task. EP segment 8 (Map OBT $^{\prime}$ 列

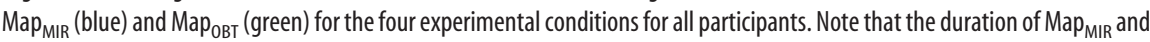
Мар $_{\text {ОВт }}$ parallels the behavioral difference in the MIR and OBT tasks, respectively, for the four experimental conditions. D, Evoked The blue and green bars estimate the time of differential coding between both tasks (in agreement with the occurrence of EPs $\mathrm{Map}_{\mathrm{MIR}}$ and $\mathrm{Map}_{\mathrm{OBT}}$, respectively). $\boldsymbol{E}$, Generators of $\mathrm{Map}_{\text {MIR }}$ (top row) were localized at the left EBA and of Map ${ }_{\mathrm{OBT}}$ (bottom row) at

dition than in back condition (mean error rates, $12.9 \pm 10.9 \%$ front; $7.2 \pm 7.5 \%$, back; $\left.F_{(1,13)}=7.85 ; p=0.015\right)$.

EP mapping of the group-averaged data revealed two distinct time segments of stable voltage topography (or EP maps) that differentially related to the MIR and OBT task, respectively, suggesting a double dissociation between these two tasks in terms of brain activation. These EP maps appeared between 250 and 450 $\mathrm{ms}$ after visual stimulus onset in two distinct time segments [Fig. $2 B$, early blue (MIR) vs later green (OBT) segments]. The earlier

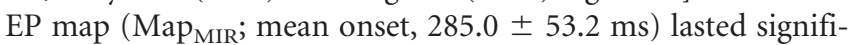
cantly longer in the MIR than in the OBT task $\left(F_{(1,13)}=6.9 ; p=\right.$ 0.02 ) (Fig. $2 B, C$ ) and hence is likely to reflect brain activation associated with the MIR task. There was no significant orientation (back-facing vs front-facing) effect for this segment 
A

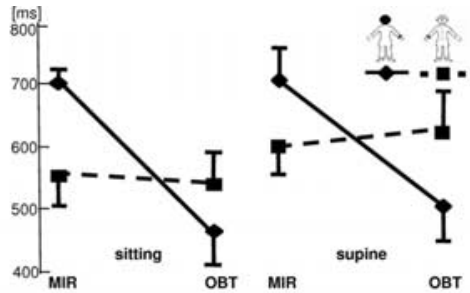

C

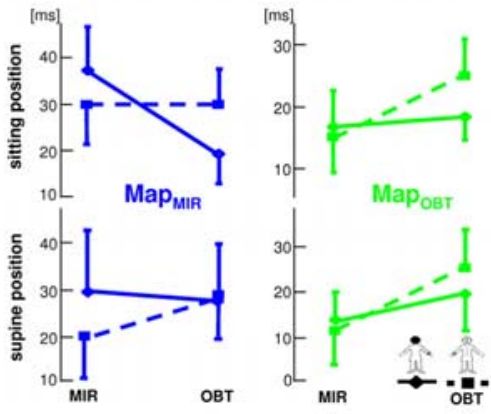

B
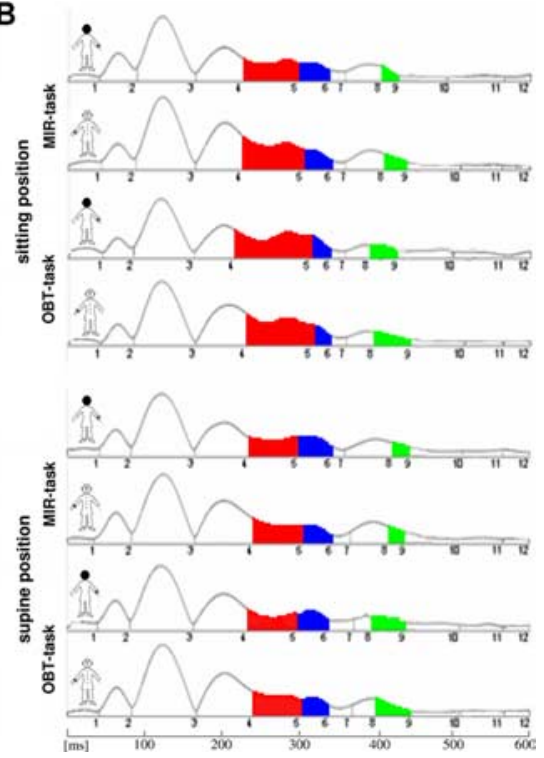

Figure 3. Behavioral and EP data during the MIR task and the OBT task in sitting and supine positions. $A$, RTs in the MIR and OBT tasks in the sitting (left) and supine (right) positions. RTs are plotted separately for front-facing (squares, dashed line) and back-facing (diamonds) figures. Error bars indicate intersubject SEM. Note that, in the two positions, there were longer RTs for the MIR task than for the OBT task, as well as orientation (back-front) effect and interaction between the task and orientation. $\boldsymbol{B}$, Segments of stable map topography in the eight experimental conditions under the global field power curve from 0 to $600 \mathrm{~ms}$. EP

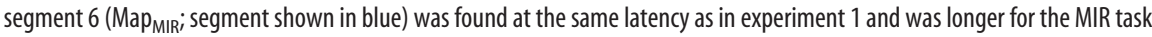
than for the OBT task in the sitting position but not in the supine position. EP segment 9 ( Map $_{0 \mathrm{BT}} ;$; segment shown in green) was also found at the same latency as in experiment 1 and was longer for the OBT task than for the MIR task in both body positions. EP

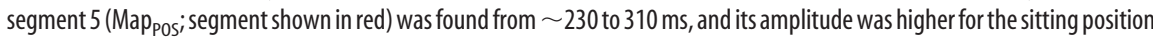
than to the supine position in the two tasks. C, Duration of $\mathrm{Map}_{\text {MIR }}$ (blue) and Map ${ }_{\text {OВт }}$ (green) for the eight experimental conditions for all participants in the sitting (top row) and supine (bottom row) positions. Note the difference in Map $\mathrm{MIR}_{\text {B }}$ between the two positions that was not found for $\mathrm{Map}_{\mathrm{OB}}$.

$\left(F_{(1,13)}=0.97 ; p=0.34\right)$, but the task $\times$ orientation interaction was significant $\left(F_{(1,13)}=5.3 ; p=0.03\right.$ ) (Fig. 2C) (supplemental Table S1, available at www.jneurosci.org as supplemental material). The later EP map (Мар $378.8 \pm 32.8 \mathrm{~ms}$ ) lasted longer in the OBT than in the MIR task $\left(F_{(1,13)}=7.4 ; p=0.02\right.$ ) (Fig. $\left.2 B, C\right)$, hence reflecting brain activation that is more engaged for the OBT task. Again, there was no significant orientation (back-facing vs front-facing) effect $\left(F_{(1,13)}\right.$ $=0.83 ; p=0.38)$, but there was a significant interaction between task and orientation for $\operatorname{Map}_{\text {ОвT }}\left(F_{(1,13)}=5.4 ; p=0.03\right)($ Fig. $2 C$ ) (supplemental Table S1, available at www.jneurosci.org as supplemental material). Analysis revealed that the onset, duration, and topography of Мар овт corresponded to the map described in the same task in an independent study sample (Blanke et al., 2005). A linear inverse solution [LAURA (Grave de Peralta Menendez et al., 2001, 2004)] localized Map ${ }_{\mathrm{MIR}}$ to the left EBA [Talairach coordinates of maximal peak $(x, y, z),(-48,-67,3)]$ and bilateral occipital cortex (Fig. 2E). Мар овт was localized to the right TPJ [maximal peak, $(54,-48,7)$ ], left EBA [maximal peak, $(-44,-69,3)]$, and bilateral occipital cortex (Fig. $2 E)$, corroborating previous results (Blanke et al., 2005).

The opposite patterns in the behavioral results of the two tasks with respect to front- and back-facing figures (Fig. 2A) suggest that participants performed the tasks as requested using an embodied (MIR task) or disembodied (OBT task) self location. These behavioral differences were also reflected in brain activation patterns (Fig. 2C), suggesting that participants used mental imagery to perform the task because, for example, rule-based decision making should be associated with the same map in both tasks and cannot easily account for these EP differences. These differences cannot be accounted for by differences in visual stimuli, orientation, and rotation of the visuospatial perspective (front-back), right-left decisions, or own-body imagery per se, because these factors were identical across tasks. A systematic difference concerns the imagined self location, i.e., embodiment (or imagined self location overlapping with the participant's body position) in the MIR task versus disembodiment (or imagined self location outside the participant's body position) in the OBT task.

Experiment 2: brain activity related to embodied, but not to disembodied, self location is affected by body position

The above results revealed behavioral and neural differences between the MIR task (involving own-body imagery with embodied self location) and the OBT task (involving own-body imagery with disembodied self location). To further test the hypothesis that these differences are attributable to differences in self location and embodiment while using own-body imagery, we performed a second experiment in which we varied the body position of our subjects (sitting vs supine) and investigated the influence of this change on performance in the MIR and OBT tasks and the underlying brain activity in an independent study sample $(n=10)$. This was based on the results of previous studies that have shown that pathological forms of embodiment in neurological patients are affected by body position (Blanke et al., 2004) and that subjects' own-body position can influence mental imagery (Corballis et al., 1976; Parsons, 1987, 1994; Mast et al., 2003). We hypothesized that our participants' body position will affect mental own-body imagery with embodied (MIR task) and disembodied self location (OBT task) differently.

RTs in both sitting and supine positions showed a similar pattern with respect to experiment 1, although RTs were faster. Performance in the MIR task showed that RTs were longer for back-facing stimuli $(699.9 \pm 130.3 \mathrm{~ms})$ than front-facing stimuli $(573.1 \pm 151.6 \mathrm{~ms})$. The opposite pattern was found in the OBT task [(longer RTs for front-facing stimuli $(577.7 \pm 204.4 \mathrm{~ms})$ than back-facing stimuli (445.9 $\pm 164.2 \mathrm{~ms})]$ (Fig. 3A). Statistical analysis revealed a significant task $\times$ orientation (back-facing vs front-facing) interaction $\left(F_{(1,9)}=25.9 ; p=0.001\right)$, a main effect of task $\left(F_{(1,9)}=8.2 ; p=0.01\right)$, and no significant orientation effect $\left(F_{(1,9)}=1.4 ; p=0.25\right)$ (supplemental Table S2, available at www.jneurosci.org as supplemental material). None of these effects or interactions were dependent on the body position $\left(F_{(1,9)}=\right.$ 1.04, $p=0.34 ; F_{(1,9)}=3.53, p=0.13 ; F_{(1,9)}=0.19, p=0.67$; respectively). For technical reasons, we always performed the tasks in the supine position first leading to a main effect of position (sitting vs supine, $540.7 \pm 157.9$ vs $625.6 \pm 196.0 \mathrm{~ms} ; F_{(1,9)}=$ $14.8 ; p=0.004$ ) as also shown by others (Vercruyssen and Simonston, 1994; McCallin et al., 1997) (see Materials and Methods). The shorter RTs in experiment 2 (if compared with those of 
experiment 1) are probably attributable to the shorter interstimulus interval in experiment 2 (see Materials and Methods).

Regarding accuracy, there were no differences between MIR and OBT tasks (mean error rates, $3.6 \pm 1.7 \%$, MIR task; $3.3 \pm 1.6 \%$, OBT task; $F_{(1,9)}=0.92 ; p=$ $0.36)$; however, subjects error rates were higher in the back condition than in front condition in the MIR task (mean error rates, $4.7 \pm 1.7 \%$, back; $3.3 \pm 1.7 \%$, front; $\left.F_{(1,9)}=10.0 ; p=0.01\right)$. The opposite pattern was revealed in the OBT task, in which error rates were higher in the front condition than in back condition (mean error rates, $3.8 \pm 1.9 \%$, front; $2.7 \pm 0.5 \%$, back; $\left.F_{(1,9)}=4.4 ; p=0.06\right)$.

EP mapping analysis of the mean EPs for the four conditions in the sitting position corroborated the results of experiment 1 (Fig. $3 B, C$ ) (for details, see Table 1 ). With respect to body position, we found that the subjects' position (sitting vs supine) in-

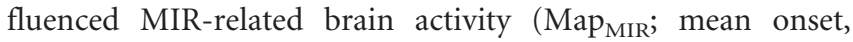
$318.1 \pm 17.3 \mathrm{~ms}$ ) (Fig. $3 B$, segment 6 , time period indicated in blue) but not OBT-related brain activity (Мар овт; mean onset, $367.4 \pm 20.6 \mathrm{~ms}$ ) (Fig. 3B, segment 9, time period indicated in green). Thus, statistical analysis revealed a task $\times$ position interaction for $\operatorname{Map}_{\mathrm{MIR}}\left(F_{(1,9)}=9.3 ; p=0.01\right)$, because Map MIR $_{\text {lasted }}$ significantly longer in the MIR task than in the OBT task in the sitting position (effect of task, $F_{(1,9)}=5.5 ; p=0.04$ ) but did not show any effect of task in the supine position $\left(F_{(1,9)}=0.07 ; p=\right.$ 0.81 ) (Fig. $3 B, C$ ). Conversely, there was no interaction task $\times$ position for Мар овт $_{\text {ов }}\left(F_{(1,9)}=0.6 ; p=0.46\right)$, because Мар овт was longer in the OBT task than in the MIR task for both the sitting $\left(F_{(1,9)}=7.5 ; p=0.02\right)$ and the supine position $\left(F_{(1,9)}=5.6 ; p=\right.$ 0.04 ) (Fig. $3 B, C$ ), i.e., independently of position (for more details, see Table 1) (for post hoc tests, see supplemental Table S2, available at www.jneurosci.org as supplemental material). To summarize, these data demonstrate that brain activation related to embodied mental own-body imagery in left EBA (MIR task) was influenced by body position, whereas brain activation related to disembodied mental own-body imagery at the right TPJ and left EBA (OBT task) was not. In addition, the results of experiment 2 in the sitting position confirmed the EP results of experiment 1 for Map $_{\mathrm{MIR}}$ and Мар sample.

EP mapping revealed no other map whose duration depended on position. However, analysis of the map strength (GFP) found a map whose activation was stronger in the sitting position (GFP, $2.03 \pm 0.97 \mu \mathrm{V})$ than in the supine position (Map POS $_{\text {S }}$ ) [Figs. $4 A$ (GFP of $1.71 \pm 0.85 \mu \mathrm{V}$ ), $3 B$, segment 5 , time period indicated in red $\left.\left(F_{(1,9)}=6.81 ; p=0.02\right)\right]$, without any significant interaction (supplemental Table S3, available at www.jneurosci.org as supplemental material). Inspection of the GFP curves in all eight experimental conditions revealed a higher GFP peak of Map (Fig. 3B, segment 5) for all sitting conditions relative to the corresponding supine conditions (Fig. $4 \mathrm{~B}$ ). No significant difference in duration was found for $\mathrm{Map}_{\mathrm{POS}}$ between the sitting position $(93.4 \pm 36.8 \mathrm{~ms})$ and the supine position $\left(93.2 \pm 29.8 \mathrm{~ms} ; F_{(1,9)}=\right.$ $0.001 ; p=0.98)$. The mean onset of Map ${ }_{\mathrm{POS}}$ was $235.5 \pm 63.1 \mathrm{~ms}$. Analysis of GFP amplitude did not reveal any differences in strength of activation for Map $_{\text {MIR }}$ and Маровт (supplemental Table S4, available at www.jneurosci.org as supplemental material). A linear inverse solution [LAURA (Grave de Peralta Menen-
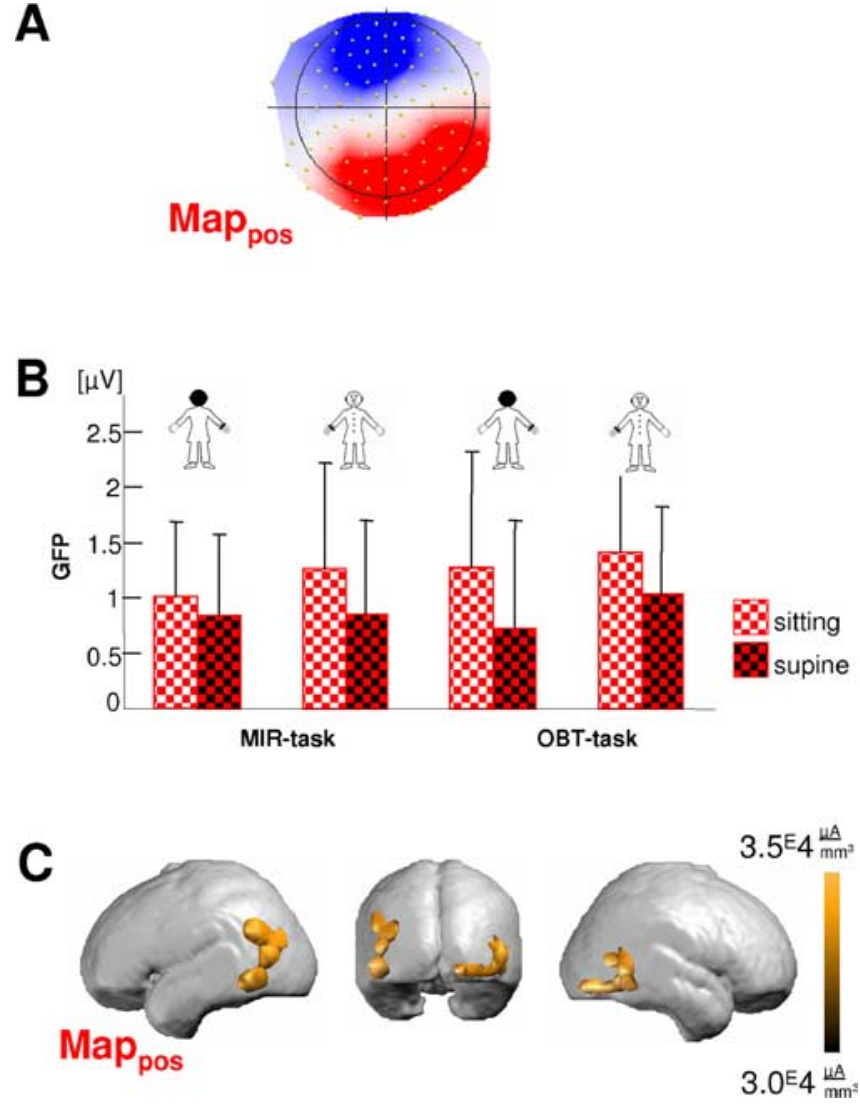

Figure 4. Analysis of Map $\mathrm{p}_{\mathrm{p} \text { S. }} \boldsymbol{A}$, Brain topography of Map ${ }_{\mathrm{p} 0 \mathrm{~s}}$. $\boldsymbol{B}$, The global field power value at $298 \mathrm{~ms}$ (peak of Map Pos $_{\text {) }}$ in the eight experimental conditions showing differential coding between sitting (white-red) and supine (black-red) positions. C, Generators of Map pos $_{\text {ore }}$ found bilaterally in EBA. Error bars indicate SEM.

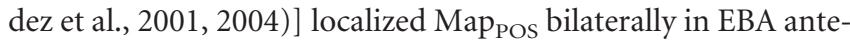
rior and dorsal to the left EBA localization found for Map $_{M I R}$ and Мар овт [(Talairach coordinates of maximal peak, right, (54, $-55,1)$; left, $(-51,-66,1)]$ and the right occipital cortex (Fig. $4 C)$. Statistical analysis revealed that brain activation before the onset and after the offset of Mappos was the same for the two positions (sitting and supine). Thus, no other EP map was found that differed in amplitude or duration between the two positions (supplemental Table S5, available at www.jneurosci.org as supplemental material). To further rule out that the observed brain activation differences between the supine and sitting positions could be explained by changes in electrode positions, contact of the electrodes with the skin, or other factors attributable to the 

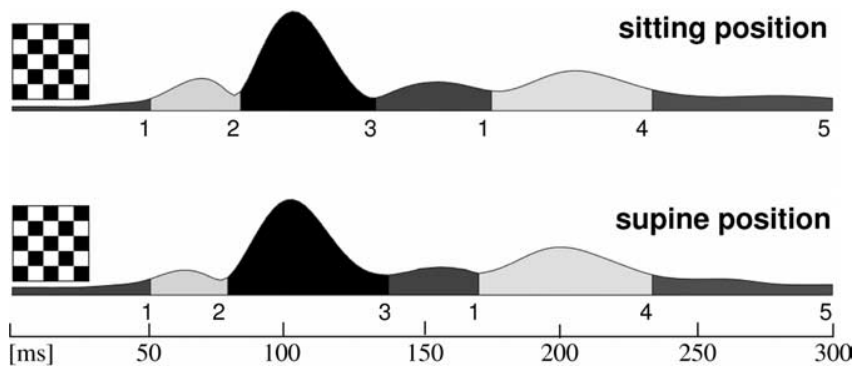

Figure 5. EP data during the checkerboard task. EP segments of stable map topography in the sitting and supine positions are shown under the global field power curve. No duration or amplitude differences were found between the two positions (top, sitting; bottom, supine; duration, $0-300 \mathrm{~ms}$ )

subject's movement from one experimental position to the other, we also performed a passive, visual control task (checkerboard stimulation; see Materials and Methods) always preceding the MIR or OBT tasks in the two different body positions. We expected that visual stimulation would lead to the same brain activation patterns, regardless of body position. This was confirmed by EP analysis, with respect to duration and amplitude of all EP components associated with this task (Fig. 5) (for details, see supplemental, Table $\mathrm{S} 6$ available at www.jneurosci.org as supplemental material). To summarize, body position influenced brain activation in EBA, which is related to embodied mental ownbody imagery (MIR task) at $\sim 318 \mathrm{~ms}$, but not later activations at TPJ and in EBA related to disembodied mental own-body imagery (OBT task). Both periods of activation were preceded (at $\sim 236 \mathrm{~ms}$ ) by a bilateral activation in EBA that was found anteriorly and dorsally with respect to later EBA activations and differed in strength depending on body position.

\section{Discussion}

\section{TPJ and EBA code differentially for self location} and embodiment

Our EP data show that mental own-body imagery activates EBA and TPJ and that the location and timing of these activations depend on whether mental own-body imagery is performed with mentally embodied (MIR task) or disembodied (OBT task) self location. Mental imagery using embodied self location activated left EBA at $\sim 318 \mathrm{~ms}$, whereas mental imagery using disembodied self location activated right TPJ and left EBA at $\sim 367 \mathrm{~ms}$. Importantly, activations at TPJ and in EBA correlate with behavioral measures showing that the activation of the right TPJ (and left EBA) was longer when subjects imagined being face-to-face with themselves (OBT task) and that the activation at the left EBA was longer when subjects imagined themselves as looking at their backs in a mirror (MIR task).

These data corroborate previous studies linking EBA to visual processing of human bodies (Downing et al., 2001; Grossman and Blake, 2002; Astafiev et al., 2004; Urgesi et al., 2004; Saxe et al., 2006) (Fig. 6). Furthermore, Astafiev et al. (2004) showed that the EBA also responds to actual and imagined movements of one's own arm, suggesting its implication in the coding of one's own body. Accordingly, it has been suggested that this region is potentially involved in self processing (Jeannerod, 2004). Here, we show that mental own-body imagery with respect to full human bodies and not only body parts (Astafiev et al., 2004) activates EBA. This activation was shown to depend on imagined body orientation (front-facing vs back-facing condition), on time period after stimulus onset $(\sim 318 \mathrm{~ms})$, and on imagined self location and embodiment (MIR task vs OBT task), suggesting that EBA activation at $\sim 318 \mathrm{~ms}$ is coding for embodiment. This EBA activation at $\sim 318 \mathrm{~ms}$ was dissociated spatially and temporally from activation of the TPJ at $\sim 367 \mathrm{~ms}$ and temporally from activation of EBA at $\sim 367 \mathrm{~ms}$. We will first consider the activation at the TPJ at $\sim 367 \mathrm{~ms}$ and later discuss EBA activations. The TPJ has been shown to be involved in multisensory coding of the human body and self (Blanke et al., 2002, 2004; Leube et al., 2003), visual processing of human bodies (Vaina et al., 2001; Beauchamp et al., 2002; Grossman and Blake, 2002), visuospatial perspective taking (Maguire et al., 1998; Vallar et al., 1999; Ruby and Decety, 2001; Vogeley and Fink, 2003), and agency (Farrell and Robertson, 2000; Chaminade and Decety, 2002; Farrer and Frith, 2002). The present study confirms that the TPJ is activated by mental own-body imagery for full human bodies (Zacks et al., 1999; Blanke et al., 2005) and that this activity depends on imagined body orientation (front-facing vs back-facing) (Blanke et al., 2005). Moreover, TPJ activation followed EBA activation by $\sim 50$ $\mathrm{ms}$ and depended differently on imagined self location by coding preferentially for a mentally disembodied self location. Collectively, these data suggest that own-body imagery activates the TPJ and EBA at different moments in time and that imagined self location and the sense of embodiment are linked to activation patterns at the TPJ and in EBA, in agreement with neuroimaging investigations in neurological patients with pathological embodiment and self location (Blanke et al., 2004, 2005; Maillard et al., 2004; Blanke and Mohr, 2005).

\section{Right and left hemisphere code differentially for self location} and embodiment

This is further suggested by the differential hemispheric activations in the present study, showing that only the left EBA was selectively activated for embodied self location at $\sim 318 \mathrm{~ms}$, whereas right TPJ and left EBA were selectively activated for disembodied self location at $\sim 367 \mathrm{~ms}$. This right hemisphere dominance of the TPJ is concordant with previous studies demonstrating right TPJ dominance as measured by various self paradigms using visuospatial perspective taking (Maguire et al., 1998; Vallar et al., 1999; Ruby and Decety, 2001; Vogeley and Fink, 2003), conceptual perspective taking (Ruby and Decety, 2001; Chaminade and Decety, 2002; Farrer and Frith, 2002; Decety and Sommerville, 2003), own-body mental imagery and illusions (Zacks et al., 1999; Blanke et al., 2005), and autobiographical memory (Conway, 2001; Levine et al., 2004). The present EP mapping study demonstrates, in addition, the involvement of the left hemisphere, in EBA, in own-body imagery for embodied and disembodied self location. The present data thus show that the coding of self location depends on when and in which hemisphere TPJ and EBA are activated.

\section{Body position signals influence brain activity}

\section{for embodiment}

We further show that body position influences brain activation during mental imagery related to embodied self location (MIR task) at the left EBA at $\sim 318 \mathrm{~ms}$. This suggests that brain activation related to self processing using mental imagery at the physical position of the body (embodied self location, MIR task) is influenced by body position changes. This was not the case for activation of the right TPJ and left EBA at $\sim 367$ ms related to self processing using mental imagery at a disembodied self location (OBT task). These results suggest that body position effects on brain activation are observed only when the mental self location spatially coincides with the physical body position. We argue that this differential position effect is attributable to an overlap be- 
tween the spatial self location and the spatial location of the body. This finding extends previous reports of body position effect on mental imagery (Corballis et al., 1976; Parsons, 1987, 1994; Mast et al., 2003).

In addition to the body position effect on brain activity related to embodied mental own-body imagery in EBA at $\sim 318 \mathrm{~ms}$, our analysis revealed an earlier and more anterior and dorsal activation at $\sim 236 \mathrm{~ms}$, whose activation strength depended on

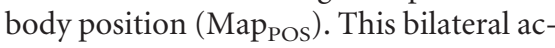
tivation was not dependent on task and was stronger in the sitting than the lying position. Anatomically, this activation might correspond to the location found by Peelen and Downing (2005) at the temporo-occipital junction anterior to the EBA during execution of unseen visually guided motor actions. Alternatively, it might be attributable to an activation of brain regions responding to static human figures and body parts such as MT+/V5 (Kourtzi and Kanwisher, 2000; Saxe et al., 2006) or to an activation of vestibular cortex (Lobel et al., 1998; Fasold et al., 2002). Both body position effects (Map POS $_{\text {and }}$ Map $_{\text {MIR }}$ ) were selective for the time window between $\sim 236$ and $\sim 318 \mathrm{~ms}$. This suggests that they are not attributable to mechanical effects on measured brain activations attributable to the different body positions, because these should have also influenced other brain activations. This was also confirmed in a separate visual control experiment that did not reveal any EP differences between the two body positions. These positional effects on self processing and embodiment also agree with observations from patients with pathological forms of self location and embodiment as autoscopy and out-of-body experience (Blanke et al., 2004; Maillard et al., 2004; Blanke and Mohr, 2005), which have been linked to different body positions.

Until now, body position effects during perception and cognition were hardly ever investigated by neuroimaging studies, because functional magnetic resonance imaging (fMRI), positron emission tomography (PET), and magnetoencephalography generally do not allow for measurements in different body positions (Alonso et al., 1989; Ouchi et al., 1999). Indeed, Raichle et al. (2001) defined the supine position of a subject with closed eyes as the default mode for brain function. Our findings might have special importance for those cognitive tasks that imply the subject's own body, because we here show that the subject's body position differentially influences brain activity in tasks using mental own-body imagery. This effect might be attributable to the influence of vestibular signals that have been shown to be involved in self- and body-related processing (Troje, 2003; Yamamoto and Yamamoto, 2006). Alternatively, differences in somatosensory coding might be related to the positional effects observed in the present study. Thus, the present data show that body position signals influence brain activations related to perception and mental imagery with respect to human bodies and the self. Because most fMRI and PET studies are performed in supine position and most EEG and magnetoencephalography studies in sitting position, studies directly comparing neuroimaging data acquired with these different techniques should take such positional effects into account. We propose that the default mode for brain function (Raichle et al., 2001) should thus be stated separately in sitting and supine positions for self- and body-related tasks.

In conclusion, the present study suggests that two distinct brain regions and their timing of activation are crucial for the sense of embodiment in humans: the EBA and the TPJ. The left EBA was found to code for embodied self location at $\sim 318 \mathrm{~ms}$, whereas the right TPJ (and left EBA) code for disembodied self location at $\sim 367 \mathrm{~ms}$. These findings also concord with anatomical and phenomenological data from neurological patients with pathological forms of self location and embodiment, such as autoscopy and out-of-body experiences, that have been recently linked to the TPJ and the EBA (Devinsky et al., 1989; Dening and Berrios, 1994; Blanke et al., 2002, 2004; Maillard et al., 2004; Blanke and Mohr, 2005). Our findings may be useful in defining the functions and brain structures mediating the self as embodied and spatially situated and may advance our understanding of pathologies concerning the disembodied self.

\section{References}

Alonso JA, Hajdu M, Gonzalez EG, Michelsen C, Semedei R (1989) Cortical somatosensory evoked potentials: effects of positional changes. Arch Phys Med Rehabil 70:194-198.

Astafiev SV, Stanley CM, Shulman GL, Corbetta M (2004) Extrastriate body area in human occipital cortex responds to the performance of motor actions. Nat Neurosci 7:542-548.

Beauchamp MS, Lee KE, Haxby JV, Martin A (2002) Parallel visual motion processing streams for manipulable objects and human movements. Neuron 34:149-159.

Blanke O, Arzy S (2005) The out-of-body experience: disturbed selfprocessing at the temporo-parietal junction. The Neuroscientist $11: 16-24$.

Blanke O, Mohr C (2005) Out-of-body experience, heautoscopy, and autoscopic hallucination of neurological origin. Implications for neurocognitive mechanisms of corporeal awareness and self-consciousness. Brain Res Brain Res Rev 50:184-199. 
Blanke O, Ortigue S, Landis T, Seeck M (2002) Stimulating illusory ownbody perceptions. Nature 419:269-270.

Blanke O, Landis T, Spinelli L, Seeck M (2004) Out-of-body experience and autoscopy of neurological origin. Brain 127:243-258.

Blanke O, Mohr C, Michel CM, Pascual-Leone A, Brugger P, Seeck M, Landis $\mathrm{T}$, Thut G (2005) Linking out-of-body experience and self processing to mental own-body imagery at the temporoparietal junction. J Neurosci 25:550-557.

Chaminade T, Decety J (2002) Leader or follower? Involvement of the inferior parietal lobule in agency. NeuroReport 13:1975-1978.

Conway MA (2001) Sensory-perceptual episodic memory and its context: autobiographical memory. Philos Trans R Soc Lond B Biol Sci 356:1375-1384.

Corballis MC, Zbrodoff J, Roldan CE (1976) What's up in mental rotation? Percept Psychophys 19:525-530.

Decety J, Sommerville JA (2003) Shared representations between self and other: a social cognitive neuroscience view. Trends Cogn Sci 7:527-533.

Dening TR, Berrios GE (1994) Autoscopic phenomena. Br J Psychiatry 165:808-817.

Devinsky O, Feldmann E, Burrowes K, Bromfield E (1989) Autoscopic phenomena with seizures. Arch Neurol 46:1080-1088.

Downing PE, Jiang Y, Shuman M, Kanwisher NA (2001) Cortical area selective for visual processing of the human body. Science 293:2470-2473.

Farrell MJ, Robertson IH (2000) The automatic updating of egocentric spatial relationships and its impairment due to right posterior cortical lesions. Neuropsychologia 38:585-595.

Farrer C, Frith CD (2002) Experiencing oneself vs. another person as being the cause of an action: the neural correlates of the experience of agency. NeuroImage 15:596-603.

Fasold O, von Brevern M, Kuhberg M, Ploner CJ, Villringer A, Lempert T, Wenzel R (2002) Human vestibular cortex as identified with caloric stimulation in functional magnetic resonance imaging. NeuroImage 17:1384-1393.

Grave de Peralta Menendez R, Gonzalez Andino S, Lantz G, Michel CM, Landis T (2001) Noninvasive localization of electromagnetic epileptic activity. I. Method descriptions and simulations. Brain Topogr 14:131-137.

Grave de Peralta Menendez R, Murray MM, Michel CM, Martuzzi R, Gonzalez Andino SL (2004) Electrical neuroimaging based on biophysical constraints. NeuroImage 21:527-539.

Grossman ED, Blake R (2002) Brain areas active during visual perception of biological motion. Neuron 35:1167-1175.

Itier RJ, Taylor MJ (2004) N170 or N1? Spatiotemporal differences between object and face processing using ERPs. Cereb Cortex 14:132-142.

Jeannerod M (2003) The mechanism of self-recognition in humans. Behav Brain Res 142:1-15.

Jeannerod M (2004) Visual and action cues contribute to the self-other distinction. Nat Neurosci 7:422-423.

Kourtzi Z, Kanwisher N (2000) Activation in human MT/MST by static images with implied motion. J Cogn Neurosci 12:48-55.

Lehmann D, Skrandies W (1980) Reference-free identification of components of checkerboard evoked multichannel potential fields. Electroencephalogr Clin Neurophysiol 48:609-621.

Leube DT, Knoblich G, Erb M, Grodd W, Bartels M, Kircher TT (2003) The neural correlates of perceiving one's own movements. NeuroImage 20:2084-2090.

Levine B, Turner GR, Tisserand D, Hevenor SJ, Graham SJ, McIntosh AR (2004) The functional neuroanatomy of episodic and semantic autobiographical remembering: a prospective functional MRI study. J Cogn Neurosci 16:1633-1646.

Lobel E, Kleine JF, Bihan DL, Leroy-Willig A, Berthoz A (1998) Functional MRI of galvanic vestibular stimulation. J Neurophysiol 80:2699-2709.

Maguire EA, Burgess N, Donnett JG, Frackowiak RS, Frith CD, O'Keefe J (1998) Knowing where and getting there: a human navigation network. Science 280:921-924.

Maillard L, Vignal JP, Anxionnat R, Taillandier-Vespignani L (2004) Semiologic value of ictal autoscopy. Epilepsia 45:391-394.
Mast FW, Ganis G, Christie S, Kosslyn SM (2003) Four types of visual mental imagery processing in upright and tilted observers. Brain Res Cogn Brain Res 17:238-247.

McCallin K, Cardenas VA, Fein G (1997) P50 event-related brain potential amplitude and suppression measurements recorded with subjects seated versus supine. Biol Psychiatry 41:902-905.

Metzinger T (2003) Being no one. The self-model theory of subjectivity. Cambridge, MA: Bradford.

Michel CM, Thut G, Morand S, Khateb A, Pegna AJ, Grave de Peralta R, Gonzalez S, Seeck M, Landis T (2001) Electric source imaging of human brain functions. Brain Res Brain Res Rev 36:108-118.

Michel CM, Murray MM, Lantz G, Gonzalez S, Spinelli L, Grave de Peralta R (2004) EEG source imaging. Clin Neurophysiol 115:2195-2222.

Murray MM, Molholm S, Michel CM, Heslenfeld DJ, Ritter W, Javitt DC, Schroeder CE, Foxe JJ (2005) Grabbing your ear: rapid auditorysomatosensory multisensory interactions in low-level sensory cortices are not constrained by stimulus alignment. Cereb Cortex 15:963-974.

Ouchi Y, Okada H, Yoshikawa E, Nobezawa S, Futatsubashi M (1999) Brain activation during maintenance of standing postures in humans. Brain 122:329-338.

Parsons LM (1987) Imagined spatial transformation of one's body. J Exp Psychol Gen 116:172-191.

Parsons LM (1994) Temporal and kinematic properties of motor behavior reflected in mentally simulated action. J Exp Psychol Hum Percept Perform 20:709-730.

Pascual-Marqui RD, Michel CM, Lehmann D (1995) Segmentation of brain electrical activity into microstates: model estimation and validation. IEEE Trans Biomed Eng 42: 658-665.

Peelen MV, Downing PE (2005) Is the extrastriate body area involved in motor actions? Nat Neurosci 8:125.

Perrin F, Pernier J, Bertrand O, Giard MH, Echallier JF (1987) Mapping of scalp potentials by surface spline interpolation. Electroencephalogr Clin Neurophysiol 66:75-81.

Raichle ME, MacLeod AM, Snyder AZ, Powers WJ, Gusnard DA, Shulman GL (2001) A default mode of brain function. Proc Natl Acad Sci USA 98:676-682.

Ruby P, Decety J (2001) Effect of subjective perspective taking during simulation of action: a PET investigation of agency. Nat Neurosci 4:546-550.

Saxe R, Kanwisher N (2003) People thinking about thinking people. The role of the temporo-parietal junction in "theory of mind." NeuroImage 19:1835-1842.

Saxe R, Jamal N, Powell L (2006) My body or yours? The effect of visual perspective on cortical body representations. Cereb Cortex 16:178-182.

Troje NF (2003) Reference frames for orientation anisotropies in face recognition and biological-motion perception. Perception 32:201-210.

Urgesi C, Berlucchi G, Aglioti SM (2004) Magnetic stimulation of extrastriate body area impairs visual processing of nonfacial body parts. Curr Biol 14:2130-2134.

Vaina LM, Solomon J, Chowdhury S, Sinha P, Belliveau JW (2001) Functional neuroanatomy of biological motion perception in humans. Proc Natl Acad Sci USA 98:11656-11661.

Vallar G, Lobel E, Galati G, Berthoz A, Pizzamiglio L, Le Bihan D (1999) A fronto-parietal system for computing the egocentric spatial frame of reference in humans. Exp Brain Res 124:281-286.

Vercruyssen MS, Simonston K (1994) Effects of posture on mental performance: we think faster on our feet than on our seat. In: Hard facts about soft machines: the ergonomics of seating (Lueder RNK, ed), pp 119-131. London: Taylor and Francis.

Vogeley K, Fink GR (2003) Neural correlates of the first-personperspective. Trends Cogn Sci 7:38-42.

Yamamoto S, Yamamoto M (2006) Effects of the gravitational vertical on the visual perception of reversible figures. Neurosci Res 55:218-221.

Zacks J, Rypma B, Gabrieli JD, Tversky B, Glover GH (1999) Imagined transformations of bodies: an fMRI investigation. Neuropsychologia 37: 1029-1040. 